\section{Tensile Strength of Glass Fiber Posts Submitted to Different Surface Treatments}

Maria Isabel A. Faria, Érica Alves Gomes, Danielle Cristine Messias, João

Manoel Silva Filho, Celso Bernardo Souza Filho, Silvana Maria Paulino
School of Dentistry, UFPR

-Federal University of Paraná,

Curitiba, PR, Brazil

Correspondence: Maria lsabel A. Faria, Rua Visconde de Nácar 865 cj 1007, 80410-201 Curitiba, PR, Brasil. Tel: +55-41-3225-1509. e-mail: mariaisabelfaria@ufpr.br

\begin{abstract}
The aim of this in vitro study was to evaluate the tensile strength of glass fiber posts submitted to different surface treatments. Forty-eight maxillary canines had their crowns sectioned and root canals endodontically treated. The roots were embedded in acrylic resin and distributed into 3 groups according to the surface treatment: Group I: the posts were treated with silane agent for $30 \mathrm{~s}$ and adhesive; Group II: the posts were cleaned with alcohol before treatment with silane agent and adhesive; Group III: the posts were submitted to conditioning with $37 \%$ phosphoric acid for 30 s before treatment with silane agent and adhesive. Each group was divided into 2 subgroups for adhesive polymerization or not before insertion into the canal: A - adhesive was not light cured and B - adhesive was light cured. All posts were cemented with Panavia F and the samples were subjected to tensile strength test in a universal testing machine at crosshead speed of $1 \mathrm{~mm} / \mathrm{min}$. Data were submitted to one-way ANOVA and Tukey's test at 5\% significance level. There was statistically significant difference $(p<0.01)$ only between group GIII-B and groups $\mathrm{GI}-\mathrm{A}$ and $\mathrm{GI}-\mathrm{B}$. No significant difference was found among the other groups ( $p>0.05$ ). It was concluded that the products used for cleaning the posts influenced the retention regardless of adhesive light curing.
\end{abstract}

Key Words: glass fiber posts, surface treatment, adhesion, tensile strength.

\section{Introduction}

The prognosis of endodontically treated teeth depends on many factors, such as teeth position in the arch, presence of adjacent teeth, occlusal contact and thickness of the remaining coronal dentin (1). In some cases, when significant loss of coronal tooth structure is observed, the restoration of endodontically treated teeth often requires intracanal posts (2).

Metallic cast posts were the most commonly used intracanal retainers, which required impression before casting in the laboratory casting (3). More recently, prefabricated posts have been widely used as a simplified and less time-consuming procedure that requires fewer visits to the dentist for tooth restoration (4). In addition, these posts present appropriate esthetics, elasticity modulus similar to dentin and uniform stress distribution along the root which decreases the risk to fracture $(2,3,5)$.

Prefabricated fiber posts are made of parallel glass fibers impregnated with a resin matrix. These posts present elasticity modulus about $25 \mathrm{GPa}$, flexural strength of 920 $\mathrm{MPa}$, resistance to compression of $340 \mathrm{MPa}(6)$, better distribution of external forces along the teeth, and better esthetics than other fiber posts $(3,5)$.

Adhesive cements are indicated for cementation of fiber posts to create mechanically homogenous units, also known as monoblocks. For this purpose, the adhesive cement must have elasticity modulus smaller than the other materials so the mechanical effort is transferred from the rigid to the flexible element when the monoblock is submitted to tensions. Furthermore, the adhesive cement absorbs great part of the tension, which avoids stress transferring to dentin and root fracture $(5,7)$.

Some factors that influence the retention of those posts and creation of a hybridization layer are preparation of dentin and post surface, use of an eugenol-containing sealer, type of adhesive agent and preparation of the posts using pliers or diamond drills $(8,9)$.

In order to provide better retention of the glass fiber posts, some authors have suggested the use of different surface treatment techniques, specially cleaning the post surface with alcohol in order to remove any grease, acid conditioning, silane application, application of a resin cement adhesive, and use of abrasive alumina blast $(8,10,11)$.

The use of alcohol (post surface cleaning), silane agent and adhesive (which is part of the resin cement) is also recommended by post manufacturers to increase retention. According to this technique, a layer of a silane agent should be applied on the post surface using a brush after cleaning the post with gauze moistened with alcohol. Then, the professional should dry the surface with a soft blow before applying the adhesive coating $(10,12)$. Additionally, some authors advocate light-polymerization 
of the adhesive agent before insertion of the post into the canal (8). Acid conditioning and abrasive blasting are also recommended in order to increase mechanical imbrication between the post and resin cement, thus increasing the retaining force $(3,5,8,9)$.

However, the literature remains inconclusive about the influence of the surface treatment of fiber posts on strengthening the retention within the root canal (8$10,12)$. So, the aim of this study was to investigate the tensile strength of glass fiber posts submitted to different surface treatments. The tested null hypotheses are: (i) there is no difference between the different techniques of glass fiber post surface treatment and (ii) light curing does not influence post retention.

\section{Material and Methods}

Forty-eight extracted maxillary human canines were used in this study. The teeth were stored in a $0.1 \%$ thymol solution at $9{ }^{\circ} \mathrm{C}$ and washed with tap water for $24 \mathrm{~h}$ for neutralization.

The teeth were endodontically treated. The crowns were removed and the root length was standardized to 15 $\mathrm{mm}$ with working length of $14 \mathrm{~mm}$. The chemomechanical root canal preparation was performed according to a crown-down manual technique and the apical stop was prepared with a flexofile instrument up to size 40 (Maillefer, Ballaigues, Switzerland). The medium and cervical thirds were prepared using Gattes Gliden drills \#2 and \#3 (Maillefer). Irrigation with $1 \% \mathrm{NaOCl}$ was conducted during the whole preparation. At the end, $10 \mathrm{~mL}$ of 17\% ETDA was used for irrigation. Final irrigation was accomplished with $10 \mathrm{~mL}$ of distilled water and the canals were aspirated and dried with absorbent paper points (Dentsply-Herpo, Petrópolis, RJ, Brazil).

Canal filling with AH Plus sealer (Dentsply DeTrey, Konstanz, Germany) was performed according to the Tagger's hybrid condensation technique. Then, the roots were immersed in distilled water before storage in the oven at $37^{\circ} \mathrm{C}\left( \pm 2{ }^{\circ} \mathrm{C}\right)$ for $36 \mathrm{~h}$, which corresponds to three times the endodontic sealer setting time. After that, the roots were individually embedded in acrylic resin (Jet, Clássico, São Paulo, SP, Brazil) using rectangular aluminum molds.

The coronal portion of the glass fiber posts was prepared with composite resin in order to create an area for grabbing the post with a $3 / 8$ shaft (Bosch, Hencho, China) connected to the Instron 4444 machine (Instron Corporation, Canton, MA, USA).

The samples were randomly assigned to 3 groups $(n=16$ each) according to the surface treatment applied to the posts: Group I: application of silane agent for $30 \mathrm{~s}$ and adhesive; Group II: cleaning with alcohol before treatment with silane agent and adhesive; Group III: 37\% phosphoric acid etching for $30 \mathrm{~s}$ before treatment with silane agent and adhesive. Each group was divided into 2 subgroups $(n=8)$, depending on whether or not the adhesive was light cured before post insertion into the canal, as follows: A: no light curing of the adhesive; $B$ : light curing of the adhesive.

The canal was prepared to a length of $10 \mathrm{~mm}$ with Largo bur \#4 (Maillefer) at a low-speed handpiece attached to a parallelometer. The canals were irrigated with $1 \%$ sodium hypochlorite and 17\% EDTA followed by a final flush with $10 \mathrm{~mL}$ of distilled water. Drying was performed by aspiration and use of absorbent paper points (Dentsply-Herpo).

Before cementation, 37\% phosphoric acid gel (Etching gel; 3M Dental Products, St Paul, MN, USA) was applied into the canal for 15 s using microbrush tips. The canal space was irrigated for $20 \mathrm{~s}$ with distilled water and dried with paper points. Later, Panavia F dual-cure resin cement (Kuraray, Osaka, Japan) was used according to the manufacturer's directions. Drops of each primer (Liquid A and Liquid B) were mixed for $5 \mathrm{~s}$ and the mixture was applied to dentin, left undisturbed for $60 \mathrm{~s}$ and gently air-thinned to evaporate the volatiles. Proper ratios of the catalyst and universal pastes were dispensed, mixed for $30 \mathrm{~s}$ to create a smooth and uniform paste, and the cement was inserted in the root canals using lentulo spirals (Maillefer).

The post-core setting was seated into the corresponding post space preparation and kept under digital pressure for $30 \mathrm{~s}$ on each surface (buccal, palatal, mesial and distal), resulting in 2-min light-curing cycles. Oxyguard II gel (Kuraray) was applied to the surface margins for $10 \mathrm{~min}$ and then removed with cotton rolls and water spray.

The samples were stored in distilled water at $37^{\circ} \mathrm{C}$ for 72 h. Later, the samples were individually attached to a custom device to be held firmly in a vertical position, in order to minimize the incidence of non-axial forces. The universal testing machine Instron 4444 (Instron Corporation) was used and the force was applied at a crosshead speed of $1.0 \mathrm{~mm} / \mathrm{min}$ until the dislodgement of each post was recorded $(\mathrm{kN})$.

Data were analyzed statistically using the Graph Pad InStat statistical software (Graph Pad Software, Inc., San Diego, CA, USA). Means and standard deviations were calculated and data were tested by one-way ANOVA. Post-hoc tests were calculated using the Tukey's multiplecomparison test. All tests were conducted at 95\% confidence interval $(\alpha=0.05)$.

\section{Results}

There was statistically significant difference $(p<0.01)$ only between the group GIII-B (acid etching + silane agent + light-cured adhesive) and the groups GI-A (silane agent + adhesive) and GI-B (alcohol + silane agent + light-cured adhesive). No significant difference was found among the 
other groups $(p>0.05)$.

\section{Discussion}

Among all prefabricated intracanal posts, the glass fiber posts have several advantages in comparison to the other posts, as an elasticity modulus similar to the dentin, lower stress, better esthetics, lower cost, no corrosion effects, preservation of tooth structure, and easy removal using rotating tools $(6,13)$. However, some factors may influence the retention of theses posts, such as post diameter and shape, cementing agent, and preparation of the dentin and post surface $(14,15)$. The first null hypothesis was rejected because significant difference was found among the techniques of glass fiber post surface treatment. However, the second null hypothesis could not be rejected as light-polymerization of the adhesive did not influence post retention

In order to achieve better performance, the glass fiber post must be fixed with resin cement agents to promote strengthening of the tooth structure and enhance esthetics (13). Thus, the resin cement Panavia F was used in this study, according to the manufacturer's instructions.

The silane agent was used in all tested groups since the post manufacturer recommends the use of a silane agent to improve retention. Some authors demonstrated that using a silane agent creates a chemical bond between the post fibers and the resin cement, which increases the retention (16-18). However, other researches have reported that using a silane agent did not increase the retention of glass fiber posts $(10,12)$.

The best results were found for the group submitted to treatment with $37 \%$ phosphoric acid for $30 \mathrm{~s}$ and subsequent adhesive light-polymerization before post insertion into the canal. The use of phosphoric acid for 30 $s$ was recommended in order to promote the elimination of particles that remain adhered to the post surface prior to its cementation (3). Acid conditioning for one minute or more is recommended to increase the interlocking between the post and the resin cement, therefore improving tensile resistance (19). The scanning electronic microscopy revealed that the post surface got rough after acid application but the fibers remained untouched with only a superficial alteration of the resin matrix (20).

Gll showed that alcohol improved the retention values in this group since the alcohol removes grease residues that are stuck on the posts and interfere in the contact between the post and silane agent or between the post and adhesive. Balbosh and Kern (9) showed that blasting a glass fiber post surface improved retention significantly. However, the use of alcohol and D/E primer on the post before cementation did not influence the retention, which is contrary to the results of this study.
There was no statistically significant difference among the groups regarding polymerization or not of the adhesive before post cementation into the root canal, demonstrating that the light-polymerization did not influence retention.

Both post surface treatments (alcohol and phosphoric acid) increased the retention values. However, other authors did not find any improvement in the glass fiber post retention, regardless the applied surface treatment (abrasive blasting, 9.6\% Hydrofluoric acid, silane agent and Cojet) $(21,22)$.

More adhesive failures were observed after treating the post, as some cement remained adhered to it after testing. Other authors reported similar failure (15,23-25) and one study reported that the critical issue regarding bond post/ cement/dentin lies on the cement/dentin interface and not on the bonds created by cement polymerization or at the cement/post interface (15).

Based on the results, it may be concluded that the best results were obtained when the posts were treated with $37 \%$ phosphoric acid for $30 \mathrm{~s}$, silane agent and lightcured adhesive. On the other hand, the worst scenario was observed for the posts treated with silane agent plus non-polymerized adhesive before insertion into the canal. Adhesive light curing per se did not influence the retention values.

\section{Resumo}

0 objetivo deste estudo in vitro foi avaliar a resistência à tração de pinos de fibra de vidro submetidos a diferentes tratamentos de superfície. Quarenta e oito caninos superiores tiveram suas coroas seccionadas e as raizes tratadas endodonticamente. As raizes foram incluídas em resina acrílica e distribuídas em 3 grupos de acordo com o tratamento de superfície aplicado aos pinos: Grupo I: os pinos receberam agente silano por 30 s e adesivo; Grupo II: os pinos foram limpos com álcool e então receberam o agente silano e adesivo; Grupo III: os pinos foram submetidos ao condicionamento com ácido fosfórico a $37 \%$ por 30 s, seguido de agente silano e adesivo. Cada grupo foi dividido em 2 subgrupos de acordo com fotoativação do adesivo antes da inserção do pino no interior do canal: A - adesivo não foi fotoativado, B: o adesivo foi fotoativado. Todos os pinos foram cimentados com Panavia Fe as amostras foram submetidas a teste de tração utilizando máquina universal de ensaios, com velocidade de $1 \mathrm{~mm} / \mathrm{min}$. Os dados obtidos foram submetidos à ANOVA a um critério e ao teste de Tukey com nivel de significância de 5\%. Houve diferença estatisticamente significante $(p<0,01)$ entre o grupo GIII-B e os grupos GI-A e GI-B. Os demais grupos não apresentaram diferenças significantes entre si $(p>0,05)$. Pode-se concluir que as substâncias utilizadas para a limpeza dos pinos interferiram em sua retenção, independente da fotopolimerização do adesivo.

\section{References}

1. Naumann M, Kiessling $S$, Seemann R. Treatment concepts for restoration of endodontically treated teeth: A nationwide survey of dentists in Germany. J Prosthet Dent 2006; 96:332-338.

2. Mitsui FH, Marchi GM, Pimenta LA, Ferraresi PM. In vitro study of fracture resistance of bovine roots using different intraradicular post systems. Quintessence Int 2004;35:612-616.

3. Dean JP, Jeansonne BG, Sarkar N. In vitro evaluation of a carbon fiber post. J Endod 1998;24:807-810.

4. Pereira JR, Neto T de M, Porto V de C, Pegoraro LF, do Valle AL. Influence 
of the remaining coronal structure on the resistance of teeth with intraradicular retainer. Braz Dent J 2005;16:197-201.

5. Ferrari M, Vichi A, Garcia-Godoy F. Clinical evaluation of fiberreinforced epoxy resin posts and cast post and cores. Am J Dent 2000;13:15B-18B.

6. Martelli R. Fourth-generation intraradicular posts for the aesthetic restoration of anterior teeth. Pract Periodontics Aesthet Dent 2000;12:579-584.

7. Faria e Silva $A L$, Arias VG, Soares LE, Martin AA, Martins LR. Influence of fiber-post translucency on the degree of conversion of a dual-cured resin cement. J Endod 2007;33:303-305.

8. Pirani C, Chersoni S, Foschi F, Piana G, Loushine RJ, Tay FR, et al.. Does hybridization of intraradicular dentin really improve fiber post retention in endodontically treated teeth? J Endod 2005;31:891-894.

9. Balbosh A, Kern M. Effect of surface treatment on retention of glass fiber endodontic posts. J Prosthet Dent 2006;95:218-223.

10. Perdigão J, Gomes $\mathrm{G}$, Lee IK. The effect of silane on the bond strengths of fiber posts. Dent Mater 2006;22:752-758.

11. Wrbas KT, Altenburger MJ, Schirrmeister JF, Bitter K, Kielbassa AM. Effect of adhesive resin cements and post surface silanization on the bond strengths of adhesively inserted fiber posts. J Endod 2007;33:840-843.

12. Bitter K, Meyer-Lückel H, Priehn K, Martus P, Kielbassa AM. Bond strengths of resin cements to fiber-reinforced composite posts. Am J Dent 2006;19:138-142.

13. Freedman GA. Esthetic post-and-core treatment. Dent Clin North Am 2001;45:103-116.

14. Stockton L, Lavelle CL, Suzuki M. Are posts mandatory for the restoration of endodontically treated teeth? Endod Dent Traumatot 1998;14:59-63.

15. Braga NM, Paulino SM, Alfredo E, Sousa-Neto MD, Vansan LP. Removal resistance of glass fiber and metallic cast post with different lengths. J Oral Sci 2006;48:15-20.
16. Park S-J, Jin J-S. Effect of silane coupling agent on interphase and performance of glass fibers/unsaturated polyester composites. J Coll Inter Sci 2001;242:174-179.

17. Bonfante G, Kaizer OB, Pegoraro LF, do Valle AL. Tensile bond strength of glass fiber posts luted with different cements. Braz Oral Res 2007;21:159-164.

18. Leme $A A$, Pinho $A L$, de Gonçalves $L$, Correr-Sobrinho $L$, Sinhoreti MA Effects of silane application on luting fiber posts using self-adhesive resin cement. J Adhes Dent 2013;15:269-274.

19. Güler AU, Kurt M, Duran I, Uludamar A, Inan O. Effects of different acids and etching times on the bond strength of glass fiber-reinforced composite root canal posts to composite core material. Quintessence Int 2012;43:e1-e8.

20. D'Arcangelo C, D'Amario M, Vadini M, De Angelis F, Caputi S. Influence of surface treatments on the flexural properties of fiber posts. J Endod 2007;33:864-867.

21. Sahafi A, Peutzfeldt A, Asmussen E, Gotfredsen K. Effect of surface treatment of prefabricated posts on bonding of resin cement. Oper Dent 2004;29:60-68.

22. Mohsen CA. Evaluation of push-out bond strength of surface treatments of two esthetic posts. Indian J Dent Res 2012;23:596-602.

23. Pithan S, Vieira R de S, Chain MC. Tensile bond strength of intracanal post in primary anterior teeth: an in vitro study. J Clin Pediatr Dent 2002;27:35-39.

24. Purton DG, Chandler NP, Qualtrough AJ. Effect of thermocycling on the retention of glass fiber root canal posts. Quintessence Int 2003;34:366369.

25. Tian $Y, M u$ Y, Setzer FC, Lu H, Qu T, Yu O. Failure of fiber posts after cementation with different adhesives with or without silanization investigated by pullout tests and scanning electron microscopy. J Endod 2012;38:1279-1282.

Received April 3, 2013 Accepted November 16, 2013 